CLINICAL TRIAIS OF RHESUS POTAVIRUS (PPV-1) VACCINE

17

Timo Vesikari ${ }^{1}, \operatorname{Tarja~Pautanen}^{1}$, A.z. Kaojkian ${ }^{2}$

1 Department of $\mathrm{Clinj}$ cal Sciences, University of Tampere, Tampere, Finland, and Laboratory of Infectious Diseases, National Institute of Allergy and Infectious Diseases, NIH, Bethesda, isd., USA

Live attenuated rhesus monkey rotavirus (RRV-1), cross-reactive with human serotype 3, was evaluated for immunogenicity and safety in 6 month-old children. A 1:10 diluted vaccine bulk (approximately $10^{6} / \mathrm{ml}$ ) given orally induced an antibody response in $21 / 24$ (88\%) of the children with high antibody titers. A febrile reaction (over $38^{\circ}$ ) on days 3 and 4 was seen in $60 \%$ of the children, and $20 \%$ of the vaccine recipients had some watery stools. It was concluded that the RRV-1 vaccine at the given dose was highly immunogenic but unacceptably reactogenic in the target population (Vesikari et al, J Infect Dis, in press).

A second trial of the RRV-1 vaccine, diluted 1:100 from the bulk (approximately $105 / \mathrm{ml}$ ) was initiated in December 1985 in 2 to 5 month-old children, who are likely to have transplacentally acouired rotavirus antibody. Preliminary analysis of 59 vaccinees indicated that about $15 \%$ had a febrile reaction (over $38^{\circ}$ ) on days 3 and 4 . The study will continue as a placebo-controlled protection study over the current rotavirus season until June 1986.

MATURATION OF THE IOWER OESOPHAGEAL SPHINCTER IN THE PRE-TERM NEONATE

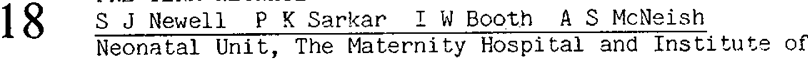
Child Health, Birmingham.

Gastro-oesoohageal reflux (GOR) is a common problem in preterm neonates, yet little is known about the maturation of the lower oesophageal sphincter (LOS). We have studied the development of the LOS using a manometric technique in non-ventilated neonates; post conceptional age (PCA) 26-40 wk, weighing 0.7-4.4 $\mathrm{kg}$. Immediately before a feed an end opening $1.5 \mathrm{~mm}$ external diameter catheter was passed pernasally into the oesophagus and the pressure measured as it was advanced through the LOS. "Effective sphincter pressure" (ESP) was calculated as LOS pressure minus gastric fundal pressure:

$\begin{array}{lcccccc}\mathrm{PCA} \text { (wik) } & 26-28 & 29-30 & 31-32 & 33-34 & 35-36 & >37 \\ \mathrm{n} & 2 & 6 & 17 & 25 & 18 & 4 \\ \mathrm{E} \mathrm{S} \mathrm{P}(\mathrm{mmHE}) & 0.7 & 4.0 & 7.3 & 7.8 & 11.0 & 13.8 \\ \text { mean +SEM } & - & +1.2 & +0.7 & +0.6 & +1.0 & -\end{array}$

In contrast to previous studies, there was a close correlation between ESP and PCA $(p<<0.001)$. The correlation of ESP with post natal age and weight was less marked though still significant $(p<0.01)$. These findings offer a rational explanation for the high incidence of $\mathrm{GOR}$ in pre-term infants.

19

MECHANISMS OF GASTROESOPHAGEAL REFLUX(GER) AND DISTAL SOPHAGEAL MOTILITY IN CHILDREN WITH GER DISEASE(GERD) S.Cucchiara; A.Staiano, C.Di Lorenzo and G.de Ritis We investigated the mechanisms of GER and esophageal motility, at the occurrence of GER, by simultaneous pressure and $\mathrm{pH}$ measurement of the distal esophagus, in 17 patients(pts) with GERD alone (range age:3-18 months) (Apts) and in 10 pts with GERD and esophagitis as sessed by histology (range age: 4-19 months) (Bpts). In A and B pts respectively, GER occurred by inappropriate transient lower esopha geal sphincter(LES) relaxation(LESr) $(378 ; 628 ; \mathrm{p}<0.005)$, deglutitive $\operatorname{LESr}(218 ; 58 ; p<0.05)$, increased gastric pressure $(148 ; 88 ; N S)$, low LES pressure $(148 ; 128 ; \mathrm{NS})$, and by combined mechanisms $(148 ; 13 \%$,NS) . During reflux episodes anplitude $(\mathrm{mmHg})($ mean $+\mathrm{SD})$ of primary per $\underline{i}$ stalsis(PrPe) was $76.1+24.1$ in Apts and $47.03+10.5$ in Bpts $(p<0.05)$; PrPe was more efficacious(rise of intraluminal pH by at least $1 \mathrm{U})$ in Apts $(62.38)$ than in Bpts $(32.7 \%)(\mathrm{p}<0.0001)$; non peristaltic waves were more common in Bpts(21.8z) than in Apts (10.98) $(p<0.025)$. Conclusions:1) the major mechanisms of GER in pts with esophagitis is an inappropriate LES relaxation.2) GER by deglutitive LES relaxation is associated with less severe GERD. 3) pts with esophagitis exhibit a deranged esophageal motility during acid exposure.
CONTINUOUS 24 H ESOPHAGEAL PH MONITORING IN 20200 ASYMPTOMATIC INFANTS (FROM 0 TO Department of Pediatrics (Prof $\mathrm{H}$ Loeb), Academic Hosp Free Univ of Brussels, BELGIUM.

A continuous $24 \mathrm{~h}$ esophageal pH monitoring, a nonagressive investigation technique in physiological circumstances, was performed in 200 asymptomatic infants between 5 days and 15 months old with a Memolog 600 system. During $24 \mathrm{~h}, 1 \mathrm{pH}$ value every $7.5 \mathrm{~s}$ was stored in memory. Several parameters (refluxindex (RI), average duration of the longest reflux episode, number of all reflux episodes and those $>5 \mathrm{~min}$ ) were studied in different groups of infants according to their age : 515 days old, $1,2,4,6,8,15$ months.

For all parameters we obtained significantly different results in infants younger and older than 4 months The RI e.g. in newborns is $1.16 \%$. This index increases to $1.78 \%$ at 1 month, to $2.53 \%$ at 2 months. At 4 months differences are significant $(\mathrm{P}<0.01$ to $\mathrm{RI}$ at 2 months; $\mathrm{P}<0.001$ to $\mathrm{RI}$ at 1 month or neonatal) as the RI reaches $4.21 \%$. At 6 months RI is $3.22 \%$, at 8 months $3.85 \%$. At 15 months finally RI decreases to $2.558 \quad(\mathrm{P}<0.01$ to $R I$ at 4 or 8 months). Our data stress the importance to establish age-related ranges for physiologic GER incidence in asymptomatic infants.

\section{THE ONTOGENY OF SMALL TNIESTINAL MOTOR ACTIVITY}

\section{W M Bisset, $J$ Watt, R Rivers, P Milla.}

St Mary's Hospital, London W2, Institute of Child Health London WCl

Three patterns of fasting small intestinal motor activity are found with increasing gestational maturity, disorganised,foetal, and migrating complex. These patterns are associated with development of the smooth muscle cell, enteric nerves and the humoral enviroment.

Using constantly perfused multilumen nasojejunal catheters we have studied the development of small intestinal smooth muscle function and its control mechanisms in 12 preterm infants studied on 24 occasions between 28 and 44 weeks gestation. With increasing maturity well defined changes in motor function occur, gastric antral pressure (10-40cril20 p<0.001), average duodenal pressure (3-15comH20 $\mathrm{p}<0.0001)$, propagated activity index ( $<<0.0001$ ), and slow wave frequency (10.5$\mathrm{p}<0.0001)$, propagated activity index $(\mathrm{p}<0.0001$ ), and slow wave frequency (10.5$12.5 \mathrm{cpm} p=0.0001$ ) all increased in a highly significant fashion. From the age
of 32 weeks there was a significant increase in the presence of postprandial activity in response to enteral nutrition. This development profile was delayed in ill infants who were ventilated for RDS and received parenteral nutrition.

These data suggest that initially there is maturation of the smooth muscle followed by the development of control systems by the enteric nerves and the humoral envirorment. Gestation, well being, and nutritional status are determinants of motor development, and a knowledge of the pattern of development and the determinants now allows prediction of the stage of motor development reached. Such information may be useful in planning the introduction of enteral feeds.

\section{2}

TRIMEBUTINE INDUCES MIGRATING MOTOR COMPLEXES IN INFANTS.

Boige_N, Cargill G, Mashako L, Cézard J.P, Navarro J Service de gastro-entérologie pédiatrique, Hôpital Bretonneau - 75018 - PARIS -

Trimebutine (TMB) induces migrating motor complexes (MMC) in dogs and in healthy adults. We have tested the effect of TMB on duodenal motility in children with severe digestive diseases requiring total parenteral nutrition, and with clinical features of dismotility. Five male children were studied (mean age $11.7 \pm$ 6.8 months) : 2 protracted diarrhea, 2 intestinal pseudo-obstruc tion, one short bowel syndrome. Fasting duodenal motor activity was recorded by manometry during 3 hours, using a two ty was recorded by manometry during 3 hours, using a two total absence of MMC and a marked hypomotility with motor indexes significantly lower than in control subjects $(\mathrm{p}<0.02)$. Intravenous administration of TMB, $3 \mathrm{mg} / \mathrm{kg}$ in $1 \mathrm{~min} 30 \mathrm{sec}$ raised a phase Wr-Like activity in 4 cases : mean delay of apparition after end of IV $88+121 \mathrm{sec}$, mean duration of phase III $236+105 \mathrm{sec}$, basal electrical rythm $12.75+0.86$ cycles/ min. An aboral propagation of the activity front was observed in 2 cases. TMB administration was followed by signs of peristalsis in 2 cases.

We conclude that TMB is able to induce MMC in unspecific motor disturbances, and may be very useful in improving the motor component of severe digestive diseases. 